\title{
Chapter 4 \\ A Life Course Perspective on Body Size and Cardio-metabolic Health
}

\author{
William Johnson, Diana Kuh, and Rebecca Hardy
}

\section{Introduction}

During the twentieth century, populations around the world experienced an epidemiological transition, with morbidity and mortality increasingly being due to non-communicable diseases such as coronary heart disease (CHD) as opposed to communicable diseases such as influenza (Omran 1971). From a peak in the 1960s and 1970s rates of CHD have fallen in many of these countries, a fall which reflects both reduced incidence of disease and better treatment resulting in reduced case fatality rates (Beaglehole 1999). More recent analysis suggests that in England, CHD mortality has continued to decrease, although with variations by socioeconomic circumstances (Bajekal et al. 2013). Despite this fall, cardiometabolic disease such as CHD, stroke, and type two diabetes, remain the leading cause of death in high income countries and are an increasing cause of morbidity and mortality in low and middle income countries (Yusuf et al. 2001). These diseases occur due to the impairment of an individual's cardiovascular system and/or metabolism and the risk of such diseases therefore reflects an individuals' cardio-metabolic health and thus measures of blood pressure, lipid, and glucose levels provide markers of cardio-metabolic health across the life course. The

\footnotetext{
W. Johnson $(\square)$

MRC Human Nutrition Research, Elsie Widdowson Laboratory, Cambridge, UK

e-mail: William.Johnson@mrc-hnr.cam.ac.uk

D. Kuh • R. Hardy

MRC Unit for Lifelong Health and Ageing at UCL, London, UK

e-mail:d.kuh@ucl.ac.uk; rebecca.hardy@ucl.ac.uk 
prevailing aetiological model for cardio-metabolic disease of the twentieth century emphasised adulthood risk factors because the diseases normally manifest for the first time in adulthood and are modifiable by lifestyle or environmental factors, such as diet, physical activity, and smoking.

Despite the dominance of the adult lifestyle model, there were a few initial reports suggesting that early life events might have long-term consequences for cardio-metabolic health in adulthood (Forsdahl 1977; Dorner et al. 1973; Dorner 1973; Freinkel 1980; Kermack et al. 2001). The study of Forsdahl (1977), for example, demonstrated a positive correlation between county level CHD mortality in Norway, in people aged between 40 and 69 years of age, and infant mortality 70 years earlier. It was postulated that poverty and food insecurity in childhood and adolescence were risk factors for CHD in adulthood. Finding a similar association between area level infant mortality and CHD mortality in the United Kingdom (UK), Professor David Barker from the University of Southampton hypothesised that environmental factors acting in utero or infancy may have adverse effects on CHD in later life (Barker and Osmond 1986). Direct evidence in support of this hypothesis was provided when Barker et al. (1989), linking individual birth records from the early decades of the twentieth century to subsequent mortality information, observed that the risk of death from CHD was greatest in individuals who were lightest at birth; birth weight being a conveniently available proxy marker of growth and nutrition in utero. A series of epidemiological studies followed seeking to confirm the initial birth weight-CHD association and extend it to include measures of postnatal growth and other health outcomes. The initial foetal origins of adult disease or programming hypothesis thus broadened, to become what is now known as the developmental origins of health and disease (DOHaD) model.

The importance of early life does not, however, mean that cardio-metabolic risk is set at the end of infancy and neither does it invalidate other models of disease causation. Indeed, at the same time that the $\mathrm{DOHaD}$ paradigm was developing, the term life course epidemiology was coined by scientists who recognised that disease development was more likely a lifelong process. They set out the key principles of this holistic approach in a series of papers and a book (Kuh et al. 2003, 2013; Ben-Shlomo and Kuh 2002; Kuh and Ben-Shlomo 2004; Kuh and Hardy 2002; Pickles et al. 2007; Lawlor and Mishra 2009; Koenen et al. 2013). Perhaps unsurprisingly, the role of body size in cardio-metabolic health played a central part in the development of the life course approach. The broad goal of this chapter is to synthesis this literature to better understand the lifelong age-related changes in body size that are indicative of poor cardio-metabolic health and the key environmental exposures and biological pathways responsible. We start with an overview of the life course approach in epidemiology to provide a framework for the review. 


\section{The Life Course Perspective}

\section{Definition}

The life course approach to epidemiology focuses on investigation of the biological, behavioural, and social pathways (that may operate across generations) that link physical and social exposures and experiences during gestation, infancy, childhood, adolescence, and adulthood with health and disease risk in an individual (and possibly their descendants) (Ben-Shlomo and Kuh 2002; Kuh et al. 2003). Initially, the focus was on chronic degenerative diseases, particularly those pertaining to cardio-metabolic and respiratory systems, where the life course perspective was used to extend the DOHaD paradigm and integrate it with apparently conflicting theories of disease aetiology, namely adult lifestyle and social causation (Marmot et al. 1984; Krieger 2013). The life course approach then widened its gaze to a broader set of functional outcomes (e.g., grip strength and blood pressure) and emphasised the importance of age-related changes in physical and cognitive capability and the physiological systems on which they depend (Kuh et al. 2013).

\section{From Conceptual Models to Trajectories}

Conceptual models are a useful way to think about how an exposure measured across the life course may influence future health. The original conceptual life course models in epidemiology were developed to test the importance of timing and duration of exposures on disease risk (Ben-Shlomo and Kuh 2002; Kuh and Ben-Shlomo 2004; Kuh et al. 2003). The critical or sensitive period model depicts a scenario where some exposure has lifelong implications for disease risk, but only if (in the case of a critical period) or most strongly when (in the case of a sensitive period) that exposure occurs during some specific age window of development. The accumulation of risk model depicts a scenario where there is cumulative damage to biological systems due to multiple exposures over the life course, which may or may not cluster together. Finally, the chain of risk model depicts a scenario where an exposure at one age influences the likelihood of experiencing the same or a different exposure at a second age, and so on until the outcome occurs. If only the last exposure in the link influences disease risk, the model is said to include a trigger effect. Alternatively, if the exposures also have direct effects on the outcome that do not operate through subsequent exposures, the model is said to be additive. This can be thought of as a hybrid model comprising a chain of risk with some accumulation of risk. 
These three types of model clearly do not capture the complexity of real life but they do provide a starting point for the conceptualisation of research questions, encourage consideration of duration, timing and order of exposures and aid effective communication of ideas. The initial emphasis in life course epidemiology had been in exploiting birth cohort studies to test what exposures measured across different periods of early life affected health and disease at a single time point in older age, but this emphasis is now moving toward gaining a better understanding of age-related disease processes and their life course determinants using the repeated measurements of health and function now available in many maturing cohort studies (Kuh et al. 2013). Such trajectories may themselves provide novel information on the disease process (e.g., how does blood pressure change over age?), maybe related to some future outcome (e.g., how are blood pressure trajectories related to CHD risk?) or concurrent process (how are blood pressure trajectories related to body weight trajectories?), or might themselves be the outcome (how is parental education associated with offspring blood pressure trajectories?). The statistical techniques needed to answer such questions are naturally becoming more and more advanced, and the reader wanting to learn more about methodology is directed to the following publications (De Stavola et al. 2006; Pickles et al. 2007; Tu et al. 2013; Johnson 2014).

\section{Deleterious Body Size Trajectories}

This section is split into life course stages. The summary compiles this information to discuss the lifelong age-related body size trajectories that are indicative of the worst cardio-metabolic health.

\section{Gestation}

Measurement of a baby at birth is the easiest way to assess the total growth experienced in gestation. In 1989, the first study to report on the relationship of birth weight with CHD was carried out in Hertfordshire, UK in 5,654 males born 1911-1930 (Barker et al. 1989). Standardised mortality ratios fell from 1.1 in men who weighed less than $2.5 \mathrm{~kg}$ to 0.8 in men who weighed more than $4.5 \mathrm{~kg}$; a similar trend in women was subsequently reported (Osmond et al. 1993). Over the next few years, publications on UK studies established birth weight as also having a negative association with central obesity (Law et al. 1992), hypertension (Barker et al. 1990), stroke (Martyn et al. 1996), autoimmune thyroid disease (Phillips et al. 1993), chronic obstructive pulmonary disease (Barker et al. 1991), and type two diabetes (Hales et al. 1991) in adulthood. Ensuing work in the MRC National Survey of Health and Development of men and women born in Britain in 1946 found an inverse relationship of birth weight with blood pressure in midlife, as has been 
demonstrated in systematic reviews of available evidence (Huxley et al. 2002), but did not find higher birth weight to be strongly associated with a slower increase in blood pressure from 36 to 53 years (Hardy et al. 2003).

The birth weight-CHD association has now been replicated across multiple studies in Europe, North America, and South Asia (Stein et al. 1996). Many of the European studies demonstrated an association independent of confounding by gestational age and socioeconomic position. Nonetheless, the confounding structure has been widely debated in publications focusing largely on blood pressure (Hardy et al. 2006b; Huxley et al. 2002), as was the proposal that the negative associations may be a statistical artefact due to over-adjustment for adulthood body size (Tu et al. 2005). A potential reversal of the birth weight-blood pressure association from positive to negative on adjustment for adult size may occur because any relationship of birth weight with adulthood body mass index (BMI), a measure of weight standardised for height that is often used as an indicator of adiposity, is generally agreed to be positive not negative (Schellong et al. 2012). This is thought to be because birth weight is strongly predictive of later fat-free mass, arguably the largest component of BMI, and to a much lesser extent adiposity (Wells et al. 2007). From the start, there was also dispute about whether the relationships with birth weight, and particularly that for type two diabetes, were linear or U-shaped (Harder et al. 2007; Whincup et al. 2008).

Birth phenotypes other than birth weight identified as being associated with increased disease risk included short length, small head circumference, and low birth weight for placental weight (Barker et al. 1990, 1992, 1993), thereby suggesting that any form of growth restriction in utero has negative consequences. We do know from cohort comparison and famine studies, in which samples of pregnant mothers were exposed to chronic undernutrition, that brain tissue and adiposity are among the last body compartments to be affected (Yajnik et al. 2003; Z. Stein and Susser 1975). Compared to UK babies of healthy well-nourished mothers, for example, those born in rural India into a food insecure environment are smaller in all dimensions $(-2.4$ $\mathrm{Z}$-scores for abdominal circumference), but least so for adiposity ( $-0.5 \mathrm{Z}$-scores for subscapular skinfold thickness) (Yajnik et al. 2003).

\section{Infancy}

The Hertfordshire Cohort Study also included health visitor records of weight at 1 year of age. Weight at this point in infancy actually had a stronger negative association with CHD than did weight at birth. Standardised mortality ratios fell from 1.1 in men who weighed less than $8.2 \mathrm{~kg}$ to 0.4 in men who weighed more than $12.2 \mathrm{~kg}$ (Barker et al. 1989). Infant weight also had a negative association with type two diabetes (Hales et al. 1991), but not with autoimmune thyroid disease (Phillips et al. 1993). The first publication to consider weight gain found that the greatest risk of CHD in men was in those born light who remained light at age 1 year, but in women was in those born light but who were heavy at age 1 
year (Osmond et al. 1993); this sex difference was not discussed by the authors. Following studies generally found low weight gain and poor growth in infancy to be deleteriously associated with future cardio-metabolic outcomes (Eriksson et al. 2003b; Forsen et al. 2004). Today, rapid infant weight gain is known to be associated with obesity and obesity-related diseases (Kerkhof and Hokken-Koelega 2012; Druet et al. 2012). A recent meta-analysis of approximately 50,000 individuals in high income countries found that gaining weight between birth and age 1 year greater than one centile band on a growth chart was associated with a $23 \%$ increased odds of adulthood obesity, for example (Druet et al. 2012). So, how does this not contradict the findings of the earlier studies? In those older cohorts, there would have been more environmental constraint on growth, thereby resulting in an at risk group who were born small and light and failed to catch-up in infancy with their better nourished peers. In the more recent studies, however, there would have been less constraint and more exposure to an obesogenic environment, thereby resulting in an at risk group who were not necessarily born small and light but nonetheless demonstrated rapid weight gain. Indeed, rapid infant weight gain is not necessarily deleterious if it occurs proportionally to increases in length (Belfort and Gillman 2013), and may even be protective in older cohorts and in low to middle income countries where it incurs gains in fat-free mass more so than adiposity (Wells et al. 2012; Bann et al. 2014).

The BMI is often used as a proxy for adiposity, despite never being intended for this purpose. Nonetheless, like percentage body fat, BMI shows a complex pattern of age-related change that can be summarised by the timing and magnitude of the maximum or peak value in infancy (Johnson et al. 2013b). Two studies have reported associations of both later timing and greater magnitude of this infant BMI peak with higher BMI later in life, one study in childhood (Silverwood et al. 2009) and one in adulthood (Sovio et al. 2014). In fully adjusted models in the latter study, a two standard deviation (SD) increase in age at peak was associated with a $1.58 \%$ change in BMI at age 31 years and a two SD increase in magnitude of peak with a $4.65 \%$ change. This finding is seemingly paradoxical to the observation of a secular trend toward earlier and lower peak as the environment has become more obesogenic (Johnson et al. 2013b). Changes in childhood BMI often reflect changes in fat-free mass more so than fat mass (Demerath et al. 2006), so it is not unreasonable to hypothesise that the positive infant peak-adulthood obesity association is driven by reduced fat-free mass in adults who experienced early and/or low peak. In agreement with the initial studies, the group of infants at risk has been proposed to comprise those with consistently low BMI in infancy (Rolland-Cachera and Peneau 2013).

\section{Childhood}

The BMI decreases in early childhood to a nadir named the adiposity rebound that occurs in most individuals between 5 and 7 years of age (Rolland-Cachera et al. 1984). Early occurrence of the rebound is associated with obesity and obesity- 
related diseases, even in the absence of elevated BMI at the age of rebound (Taylor et al. 2005), although this has been hotly debated in the past (Cole 2004). The most deleterious pattern is characterised by an early rebound and the crossing over of trajectory from low to high BMI (Rolland-Cachera and Peneau 2013). This pattern is in agreement with most secular trend studies (Johnson et al. 2012a), systematic reviews (Owen et al. 2009), and the initial studies (Barker et al. 2005). In the Helsinki Birth Cohort Study, for example, early rebound (less than 5 years of age) compared to late rebound (greater than 7 years of age) was associated with lower BMI in infancy, but higher BMI and cumulative incidence of type two diabetes (8.6 versus 1.8) in adulthood (Eriksson et al. 2003a). This crossing over of trajectory in children with an early rebound is driven by changes in adiposity rather than fatfree mass (Taylor et al. 2004). In contrast, the relationship of BMI at age 6 years to BMI at all previous and subsequent ages is driven by tracking of fat-free mass as well as adiposity (Rolland-Cachera and Peneau 2013). The rebound may, therefore, be a particularly important part of the establishment or otherwise of a deleterious trajectory (see section "Critical Periods and Transitions").

In addition to rapid weight gainers perhaps following an early rebound, there is likely to be a separate group whose poor growth persists in childhood (Cameron 2007). Both groups were identified as being at increased risk of hypertension in adulthood in the Helsinki Birth Cohort Study (Eriksson et al. 2007). Interestingly, the former trajectory had previously been reported to be associated with CHD (Barker et al. 2005), while the later had been reported to be associated with stroke (Osmond et al. 2007). Writing in a review paper, Barker et al. (2009) explains that the co-existence of these trajectories "casts light on the differing ecologies of CHD and stroke, for both of which hypertension is a risk factor". Rates of both CHD and childhood obesity, perhaps contributed to by rapid weight gain, increase as countries go through the epidemiological transition, but stroke remains most prevalent in low income countries where children tend to be short and thin.

\section{Adolescence}

Trajectories of children at risk carry forward so that in adolescence both high $\mathrm{BMI} /$ continued rapid weight gain and small body size/continued poor growth are associated with poorer cardio-metabolic health. Further, adolescence may be a particularly important stage in the life course for the establishment of a deleterious trajectory (see section "Definition"). A meta-analysis reported a positive association (relative risk 1.09, $95 \%$ confidence interval 1.00-1.20) between BMI Z-score at 718 years of age and CHD (Owen et al. 2009). This and other meta-analyses tend to pool data across wide age ranges (Paajanen et al. 2010; Verbeeten et al. 2011) and estimates for the association of height specifically in adolescence with any cardiometabolic health or disease outcome in adulthood cannot be found in systematic review literature. Most of our knowledge about the future health consequences of poor adolescent growth comes from stand-alone studies of historical birth cohorts 
and studies in low to middle income countries (Adair et al. 2013; Johnson et al. 2014; Skidmore et al. 2007). Greater height at age 15 years has been shown to be related to lower and thus more healthy total cholesterol and carotid intima-media thickness in the MRC National Survey of Health and Development, for example (Johnson et al. 2014; Skidmore et al. 2007).

The description of adolescents at risk becomes less clear when we consider the phenomenon that obese people tend to be temporarily taller than their non-obese peers by up to $3 \mathrm{~cm}$ in adolescence (Johnson et al. 2012b; Metcalf et al. 2011). This difference is similar to the temporary greater height of some girls compared to boys during adolescence, due to their earlier maturation (Ellison and Reiches 2012). The temporary greater height of some obese adolescents most likely reflects an advanced pace of development. Indeed, numerous studies in diverse populations have shown that adolescent obesity is linked to the earlier development of secondary sexual characteristics, most of which are in turn associated with shorter adulthood height (Dunger et al. 2005; Johnson et al. 2013a). Early timing of traits such as age at menarche has been implicated in cardio-metabolic disease processes (Prentice and Viner 2013; Hardy et al. 2006a), but whether or not they precede adolescent obesity or are causally related to adulthood disease independent of adolescent obesity remains unclear (Johnson et al. 2013a; Mumby et al. 2011; Pierce et al. 2012).

\section{Adulthood}

Linear growth is complete by adulthood, so the cardio-metabolic consequences of being short are less confounded by the constant change in ranking by height of individuals that occurs earlier in life. In one meta-analysis of data from over one million adults, a $6.5 \mathrm{~cm}$ increase in height was associated with a hazard ratio of 0.97 (95\% confidence interval 0.96-0.99) for all-cause mortality (Emerging Risk Factors Collaboration 2012). A body of literature has reported similar negative associations between adulthood height and other outcomes in diverse populations (Paajanen et al. 2010; Rosenberg et al. 2013; Schmidt et al. 2013). Further, we know that leg length, as a reflection of early life adversity (Wadsworth et al. 2002), is the main component of height associated with disease development (Langenberg et al. 2003; Wadsworth et al. 2002).

BMI in early adulthood has been shown to be associated with higher risk of subsequent CHD. The meta-analysis of Owen et al. reported a positive association between BMI Z-score between 18-30 years of age and CHD (relative risk 1.19, $95 \%$ confidence interval 1.11-1.29) that was stronger than that in adolescence (Owen et al. 2009). Similar systematic reviews have been published for various cardiometabolic biomarkers and diseases (Choi et al. 2013; Rao et al. 2011). Perhaps the most conclusive study of nearly one million adults reported a U-shaped association between BMI and all-cause mortality (Whitlock et al. 2009). Deaths in people with low BMI are most likely to be smoking and cancer related, whereas deaths in people with high BMI are most likely to be related to cardio-metabolic health (Whitlock et al. 2009). 
Investigation is now focusing on whether those who were overweight in early life can alter their risk by being of normal weight in adulthood and whether duration of overweight is important. Literature has shown that obese children and adolescents who become normal weight in adulthood may have similar cardio-metabolic profiles as individuals who were always normal weight (Juonala et al. 2011; Li et al. 2012). Using data from the British birth cohort studies, however, Park et al. have reported higher odds ratios for type two diabetes in obese adults who were also overweight or obese in childhood and adolescence (odds ratio 12.6, $95 \%$ confidence interval 6.6-24.0) compared to those who were obese in adulthood only (odds ratio 5.5, $95 \%$ confidence interval 3.4-8.8), thereby suggesting that duration of exposure in addition to normalisation of weight status (i.e., change from obese/overweight to normal weight) is important (Park et al. 2013). One caveat here is that BMI tracks and increases across most of the life course, so the group who are obese in childhood and/or adolescence but normal weight in adulthood is typically small. Further, adults who are obese according to BMI may be metabolically healthy (Roberson et al. 2014). It has been hypothesized that it is this group of people who have consistently high BMI from infancy onward due to increased fat-free mass not adiposity (Rolland-Cachera and Peneau 2013). However, Ortega et al. have shown that a metabolically healthy obese group exists even when obesity is defined according to percentage body fat (Ortega et al. 2013).

\section{Summary}

The key traits associated with poor cardio-metabolic health in our literature review appear to naturally cluster into two groups. The first comprises microsomia in babies who despite being small are relatively adipose, postnatal growth failure particularly early in life, short adulthood stature and legs, and underweight or wasting/thinness at any age. Conversely, the second comprises macrosomia, rapid infant weight gain, early adiposity rebound followed by rapid BMI gain, tall stature in puberty, and peri-pubertal or adulthood obesity development. The first cluster characterises a trajectory of small size of most body dimensions and components (Fig. 4.1, Trajectory A) that might be found in older cohorts and studies in low income countries where there is constant persisting nutritional insecurity and high rates of stroke. Conversely, the second cluster characterises a trajectory of large size of most body dimensions and components (Fig. 4.1, Trajectory B), that might be found in modern day populations and high income countries where there are high rates of obesity and CHD. Most long-term follow-up studies have been conducted in cohorts that have experienced large changes in the environment over their life time or in studies in countries experiencing similar changes due to rapid nutritional and epidemiological transitions. It is perhaps, therefore, unsurprising that lying somewhere in between the first two trajectories is a third trajectory summarising this literature; it is characterised by small size and thinness at birth and in infancy, but rapid gains in weight and specifically adiposity in childhood, and the subsequent 


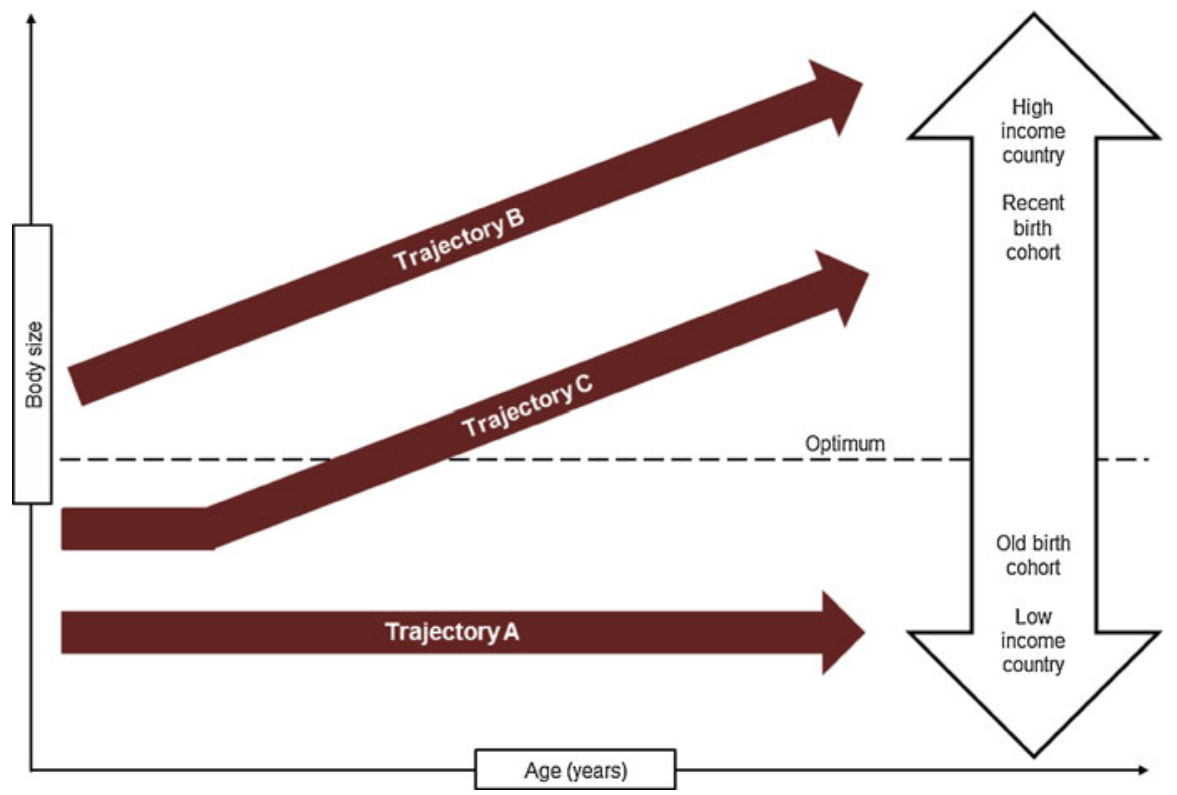

Fig. 4.1 Body size trajectories in the development of cardio-metabolic health

development of obesity and increased disease risk in response to the transitioning environment (Fig. 4.1, Trajectory C).

Clearly, the three trajectories in Fig. 4.1 are conceptual. While we split this section into life course stages for convenient handling of information, it is important to remember that each measure (e.g., weight and abdominal circumference) has its own trajectory that may follow a complex pattern of age-related change, demonstrate complex associations with cardio-metabolic health, and vary greatly between cohorts and across time, place, and population sub-groups. Further, traits in one trajectory might interact with traits in another trajectory to influence cardiometabolic health. Considering birth weight and adulthood waist circumference, for example, risk for type two diabetes is greatest for individuals born light who went on to develop large waist lines (Tian et al. 2006).

\section{Determinants and Mechanisms of Deleterious Trajectories}

An association between body size at one age and cardio-metabolic health at a second age does not mean that the former causes the later. This section seeks to explain how and why body size across the life course may be associated with cardio-metabolic health. 


\section{Environmental Exposures}

Foetal growth is ultimately restricted by uterine capacity. Babies may be born small because they are constrained in this way or because they lacked the nutrients in utero necessary for optimum growth (Harding 2001). Pregnant women exposed to famine give birth to small babies who go onto develop glucose intolerance and obesity in adulthood, for example (Ravelli et al. 1976, 1998). The proportion of protein and carbohydrate in a women's diet may be a key factor that affects the foetus, with the combination of high carbohydrate and low protein intake being particularly deleterious (Campbell et al. 1996; Godfrey et al. 1996). In addition to maternal intake per se, clinical exposures such as maternal hypertension leading to reduced uterine blood flow can severely affect the supply line of nutrients from the mother to the foetus (Harding 2001).

Other well-known determinants of size at birth include sex, gestational age, ethnic origin, parity, maternal and paternal size, gestational weight gain, general morbidity and episodic illness, malaria, cigarette smoking, and alcohol consumption (Kramer 1987). Maternal gestational diabetes is associated with higher birth weight and increased risk of subsequent obesity (Lawlor et al. 2011), but Gillman et al. (2003) have questioned the causal role of altered maternal-foetal glucose metabolism because adjusting the gestational diabetes-childhood obesity association for birth weight only marginally attenuated the estimate in their study. This might, however, be expected given that even the most exposed foetuses are limited to how much weight they can gain in utero; the greatest anatomical response to altered glucose metabolism will inevitably occur after birth, when there is no upper limit on weight gain. Indeed, the most deleterious profile for childhood obesity comprises rapid infant weight gain in addition to pre-pregnancy obesity and macroscomia (Weng et al. 2012).

Determinants of childhood obesity include maternal smoking, no or short duration of breastfeeding, obesity in infancy, short sleep duration, television viewing, low daily physical activity, and consumption of sugar-sweetened beverages (Monasta et al. 2010). Many of these risk factors continue to operate in adolescence (Morandi et al. 2012), at ages when there is increasing independence from the family and the establishment of more individual as compared to familial risk factors. Most research has focused on shifts in diet and physical activity as the key drivers of the obesity epidemic, particularly during adulthood (Swinburn et al. 2011; McAllister et al. 2009). There is, however increasing evidence for multiple other factors including microorganisms and epigenetics early in life, sleep debt, and endocrine disruptors (McAllister et al. 2009).

Naturally, the exposures responsible for obesity are very different to those for malnutrition. Evidence from low to middle income countries shows that the key determinants of stunting, wasting, and underweight include growth restriction in utero, poor condition of the mother, poverty, chronic dietary insufficiency, marked seasonality, poor levels of sanitation, and infection (Martorell and Young 2012; Frongillo et al. 1997). As these countries transition, it has been argued that the 
people are likely to face both sets of exposures and a dual burden of stunting and overweight (Varela-Silva et al. 2012). Others have, however, shown that the coexistence of stunting and overweight, at least at the family level, is a statistical artefact with a prevalence that matches what one would expect based on the separate stunting and overweight rates (Dieffenbach and Stein 2012).

\section{Biological Pathways}

Biological pathways are ultimately responsible for the links between environmental exposures, body size, and cardio-metabolic health. The first main type of pathway involves anatomical changes. Anatomical formation of the kidneys occurs exclusively in utero, and nutritional constraint of a foetus can permanently reduce the number of nephrons that are laid down, for example (Barker et al. 2006). Although physiological capability of the kidney develops over the entire life course, small kidney size in prenatally undernourished individuals increases risk for hypertension and renal failure in adulthood (Lampl et al. 2002; Luyckx and Brenner 2005). Similarly, a larger number of adipocytes in response to nutritional excess and a sedentary lifestyle in adulthood can increase CHD risk because these cells secrete inflammatory proteins that speed up the atherosclerotic process (Berg and Scherer 2005).

The second main type of pathway involves the physiological setting or alteration of hormonal and metabolic axes. For example, the foetus responds to reduced nutritional supply by reducing plasma concentrations of hormones, such as insulin and insulin-like growth factor, which in turn limits the transportation of glucose to the muscles and impairs lean tissue growth (Phillips 1996). This adaptation occurs so that glucose is readily available in the bloodstream to maintain growth of high priority organs, such as the brain (Gluckman 1995). The tendency to maintain high blood glucose levels can, however, lead to a progressive decline in glycaemic control and type two diabetes (Phillips 1996). As a different example, dysregulation of the hypothalamic-pituitary-adrenal axis in response to chronic stress in adulthood might lead through the effects of cortisol to central obesity and cardio-metabolic disease (Rosmond and Bjorntorp 2000).

One increasingly well-studied set of mechanisms focuses on the way in which genes governing body size impact on cardio-metabolic health. We know that environmental exposures can modify the expression of genes. A recent metaanalysis reported that the odds of obesity associated with the risk allele in the FTO gene was attenuated in active adults compared to inactive adults by $27 \%$, for example (Kilpelainen et al. 2011). Chemical modifications occur that alter gene expression in a specific tissue or organ without changing the nucleotide sequence of the DNA (e.g., methylation and histone modification) (Holliday 1994). While an environmental exposure may influence body size in the short term, these "epigenetic" changes can have long lasting effects on disease risk. Maternal protein restriction might lead to smaller offspring and reduce methylation (and therefore 
enhance expression) of the angiotensinogen receptor gene in the offspring adrenal gland, thereby leading to high blood pressure, for example (Bogdarina et al. 2007; Woodall et al. 1996). Such epigenetic changes can occur from conception onward but, like the other anatomical and physiological pathways, are most sensitive to the environment during specific stages of the life course.

Genes are also being used increasingly in Mendelian randomisation studies, where a genetic variant or set of variants are used as an instrumental variable for some phenotype or exposure, to establish whether or not that phenotype has a causal effect on some outcome (Lawlor et al. 2008). This technique has recently been used, for example, to demonstrate that BMI does have causal effects on various cardio-metabolic traits, including blood pressure and fasting glucose and cholesterol (Holmes et al. 2014). These studies work, subject to certain assumptions, on the premise that alleles are transmitted from parents to offspring randomly at gamete formation, such that the genotype or instrumental variable relationship with the outcome is not confounded by environmental factors or prone to reverse causation (Lawlor et al. 2008).

\section{Critical Periods and Transitions}

A critical period refers to an age window in which intrinsic changes in body structure and function are occurring rapidly and may be most easily programmed in a favourable or unfavourable direction (Scott 1986). The focus in the natural sciences was originally on the requirement of specific environmental stimuli to elicit the normal development and functioning of some body part or system (Cameron and Demerath 2002). In contrast, epidemiology focuses on the environmental exposures that result in anatomical and physiological adaptations that have longterm implications for cardio-metabolic health (Kuh et al. 2003). Perhaps the most often used example of a critical period is the teratogenic effect of maternal exposure to thalidomide in the first trimester of pregnancy on limb development in the foetus when the limbs are most rapidly developing, while exposure to thalidomide after birth is harmless (Newman 1986). In this instance, the critical period is truly critical. In other examples, however, the exposure association (with the outcome) is not constrained to such a narrow age window, but may be present across part or whole of the life course. The strongest associations are observed at ages when the individual is most sensitive to the environment, thus these are called sensitive periods of development.

Research has now identified potentially sensitive periods spanning the entire life course. Early childhood and adolescence in particular are emerging as important periods for the establishment of obesity and programming of cardio-metabolic risk. It has recently been shown in the MRC National Survey of Health and Development that socioeconomic disadvantage in early childhood, more so than at any other age, is associated with cardio-metabolic risk factors at age 53 years, for example (Murray et al. 2011). In the same cohort, exposure to obesity emerges during adolescence as 
being associated with greater carotid-intima media thickness at 60-64 years of age in men (Johnson et al. 2014). The associations reported in both of these papers were independent of birth weight and appeared to be mediated by higher adulthood BMI in those individuals who were disadvantaged in early childhood or obese in adolescence.

Adolescence is often viewed as critical from physical and behavioural perspectives, but individuals experience this stage in the life course at different ages and progress through secondary sexual characteristic maturation at different paces (Ellison and Reiches 2012). A critical or sensitive period may be thought of as a point of transition from one state to another. During puberty, for example, the adolescent transitions from an immature state to a mature state. Various markers of the pace of pubertal development have been reported to be associated with various cardio-metabolic health outcomes in both sexes (see section "Adolescence"). Interestingly, an early age at menopause, which marks the cessation of a women's reproductive ability, is also associated with increased risk for cardio-metabolic disease (Ebong et al. 2014). Lifelong environmental conditions may influence the timing of menopause (Lawlor et al. 2003), but it is unknown whether or not the biological changes that occur during menopause and impact on subsequent health are particularly sensitive to concurrent exposures. Similarly, behavioral transitions throughout the life course can lead to increased disease risk, but these do not necessarily occur at ages when biological changes are occurring rapidly and are most sensitive to the environment. Transition into a romantic relationship or marriage can cause behavioral changes that lead to the development of obesity (The and Gordon-Larsen 2009; Gordon-Larsen et al. 2004), but there is nothing biologically critical about the exact age when this occurs, for example. The same might be true for starting university (Gropper et al. 2012), leaving the army (Littman et al. 2013), and retiring (Morris et al. 1992). The timing of rapid change in a known biological structure/function is critical for the experience of specific environmental stimuli to cause permanent alterations and predict long-term outcomes (Cameron and Demerath 2002). While a critical or sensitive period may be thought of as a transition, a transition does not automatically meet the requirements to be a critical of sensitive period.

\section{Transgenerational Transmission}

Recent research in human and animal models suggests that biological adaptations to environmental exposures during critical or sensitive periods of development may be transmitted to subsequent generations (Benyshek 2013), such that a trait like insulin resistance in the exposed generation might be passed to successive unexposed generations in diminishing order of magnitude (Benyshek et al. 2006). This transgenerational transmission goes beyond something that might be explained by genetic heritability or by family members of different generations experiencing similar lifelong environments. Maternal exposure to famine, for example, has been 
shown to be associated with increased risk of giving birth to small offspring with dysregulated lipid profiles (Lumey et al. 2009), who themselves go onto have relatively small offspring with large amounts of adiposity and high risk for cardiometabolic disease (Painter et al. 2008). In this scenario, direct and simultaneous exposure of three generations (i.e., the pregnant mother, her fetus, and the fetuses' primordial germ cells) might be responsible for the increased disease risk seen in each generation. Alternatively, and if more than three generations are affected, research is revealing how inheritance of epigenetic modifications to the genome may be responsible (Hackett et al. 2013).

\section{Public Health Relevance and Conclusion}

The role of life course research in public health debates, such as whether money should be spent on the primordial prevention of cardio-metabolic diseases in high risk strata of society or whether it should be used to provide effective treatment in the smaller number of people who actually develop a disease, is to provide clear empirical evidence of how and why a disease develops. Only then is it possible to understand what physical and social exposures should be targeted and at what ages. The conclusion of Barker et al. (1989) that "promotion of postnatal growth may be especially important in boys who weigh below $7.5 \mathrm{lb}(3.4 \mathrm{~kg})$ at birth" today may appear reckless. But this is only because a whole body of life course epidemiology literature has since been published showing that, at some ages and in some populations, rapid infant weight gain leads to the deleterious development of excess adiposity and may not incur protective long-term gains in height and fatfree mass (Bann et al. 2014; Druet et al. 2012; Kerkhof and Hokken-Koelega 2012; Wells et al. 2012). We may still not be at a situation where we should attempt to increase growth rates in infants who are born small, but we are developing a clearer picture of how, when, and in what populations this might be best achieved without adversely impacting on future health (Ong and Loos 2006).

Knowledge of the life course processes that lead to poor cardio-metabolic health and disease is relevant to many public health discussions and policies, not just those relating to infant growth and obesity. The life course perspective has become a central part of the World Health Organisation's programme on non-communicable disease prevention and health promotion (World Health Organisation Dept of Noncommunicable Disease Prevention and Health Promotion 2001). Particularly in the UK, the importance of a life course approach is increasingly gaining recognition, with recent reports on mental wellbeing and reproductive health having all championed the approach (Foresight. 2008; Scientific Advisory Committee 2011). The Marmot (2010) review on reducing health inequalities in the UK included statements, such as "giving every child the best start in life" and "enabling all children, young people, and adults to maximise their capabilities and have controls over their lives". The challenge life course epidemiologists now face is to fine-tune their studies to provide policy makers with the best, actionable information. 
The literature on the relationships of body size with cardio-metabolic health is immense. Associations of body size with cardio-metabolic health can be explained in terms of anatomical and/or physiological changes in response to environmental conditions during critical or sensitive periods of development. These adaptations can persist across subsequent generations through epigenetic inheritance, thereby adding another layer of complexity to life course epidemiology. The integration of biological and social research is clearly important, as is the understanding of the processes and pathways operating across the life course. Taking this more holistic approach and understanding the life course trajectories of body size and cardiometabolic health will lead to a more complete understanding of cardio-metabolic disease processes and how to stop disease processes progressing faster in some people than others.

Open Access This chapter is distributed under the terms of the Creative Commons Attribution Noncommercial License, which permits any noncommercial use, distribution, and reproduction in any medium, provided the original author(s) and source are credited.

\section{References}

Adair, L. S., Fall, C. H., Osmond, C., Stein, A. D., Martorell, R., Ramirez-Zea, M., et al. (2013). Associations of linear growth and relative weight gain during early life with adult health and human capital in countries of low and middle income: findings from five birth cohort studies. Lancet, 382(9891), 525-534.

Bajekal, M., Scholes, S., O'Flaherty, M., Raine, R., Norman, P., \& Capewell, S. (2013). Unequal trends in coronary heart disease mortality by socioeconomic circumstances, England 19822006: An analytical study. PloS One, 8(3), e59608.

Bann, D., Wills, A., Cooper, R., Hardy, R., Aihie Sayer, A., Adams, J., et al. (2014). Birth weight and growth from infancy to late adolescence in relation to fat and lean mass in early old age: Findings from the MRC National Survey of Health and Development. International Journal of Obesity, 38(1), 69-75.

Barker, D. J., \& Osmond, C. (1986). Infant mortality, childhood nutrition, and ischaemic heart disease in England and Wales. Lancet, 1(8489), 1077-1081.

Barker, D. J., Winter, P. D., Osmond, C., Margetts, B., \& Simmonds, S. J. (1989). Weight in infancy and death from ischaemic heart disease. Lancet, 2(8663), 577-580.

Barker, D. J., Bull, A. R., Osmond, C., \& Simmonds, S. J. (1990). Fetal and placental size and risk of hypertension in adult life. British Medical Journal, 301(6746), 259-262.

Barker, D. J., Godfrey, K. M., Fall, C., Osmond, C., Winter, P. D., \& Shaheen, S. O. (1991). Relation of birth weight and childhood respiratory infection to adult lung function and death from chronic obstructive airways disease. British Medical Journal, 303(6804), 671-675.

Barker, D. J., Godfrey, K. M., Osmond, C., \& Bull, A. (1992). The relation of fetal length, ponderal index and head circumference to blood pressure and the risk of hypertension in adult life. Paediatric and Perinatal Epidemiology, 6(1), 35-44.

Barker, D. J., Osmond, C., Simmonds, S. J., \& Wield, G. A. (1993). The relation of small head circumference and thinness at birth to death from cardiovascular disease in adult life. British Medical Journal, 306(6875), 422-426.

Barker, D. J., Osmond, C., Forsen, T. J., Kajantie, E., \& Eriksson, J. G. (2005). Trajectories of growth among children who have coronary events as adults. New England Journal of Medicine, 353(17), 1802-1809. 
Barker, D. J., Bagby, S. P., \& Hanson, M. A. (2006). Mechanisms of disease: In utero programming in the pathogenesis of hypertension. Nature Clinical Practice Nephrology, 2(12), 700-707.

Barker, D. J., Osmond, C., Kajantie, E., \& Eriksson, J. G. (2009). Growth and chronic disease: Findings in the Helsinki Birth Cohort. Annals of Human Biology, 36(5), 445-458.

Beaglehole, R. (1999). International trends in coronary heart disease mortality and incidence rates. Journal of Cardiovascular Risk, 6(2), 63-68.

Belfort, M. B., \& Gillman, M. W. (2013). Healthy infant growth: What are the trade-offs in the developed world? Nestle Nutrition Institute Workshop Series, 71, 171-184.

Ben-Shlomo, Y., \& Kuh, D. (2002). A life course approach to chronic disease epidemiology: Conceptual models, empirical challenges and interdisciplinary perspectives. International Journal of Epidemiology, 31(2), 285-293.

Benyshek, D. C. (2013). The "early life" origins of obesity-related health disorders: New discoveries regarding the intergenerational transmission of developmentally programmed traits in the global cardiometabolic health crisis. American Journal of Physical Anthropology, 152(Suppl 57), 79-93.

Benyshek, D. C., Johnston, C. S., \& Martin, J. F. (2006). Glucose metabolism is altered in the adequately-nourished grand-offspring (F3 generation) of rats malnourished during gestation and perinatal life. Diabetologia, 49(5), 1117-1119.

Berg, A. H., \& Scherer, P. E. (2005). Adipose tissue, inflammation, and cardiovascular disease. Circulation Research, 96(9), 939-949.

Bogdarina, I., Welham, S., King, P. J., Burns, S. P., \& Clark, A. J. (2007). Epigenetic modification of the renin-angiotensin system in the fetal programming of hypertension. Circulation Research, 100(4), 520-526.

Cameron, N. (2007). Growth patterns in adverse environments. American Journal of Human Biology, 19(5), 615-621.

Cameron, N., \& Demerath, E. W. (2002). Critical periods in human growth and their relationship to diseases of aging. American Journal of Physical Anthropology, 119(Suppl 35), 159-184.

Campbell, D. M., Hall, M. H., Barker, D. J., Cross, J., Shiell, A. W., \& Godfrey, K. M. (1996). Diet in pregnancy and the offspring's blood pressure 40 years later. British Journal of Obstetrics and Gynaecology, 103(3), 273-280.

Choi, J., Joseph, L., \& Pilote, L. (2013). Obesity and C-reactive protein in various populations: A systematic review and meta-analysis. Obesity Reviews, 14(3), 232-244.

Cole, T. J. (2004). Children grow and horses race: Is the adiposity rebound a critical period for later obesity? BMC Pediatrics, 4, 6.

De Stavola, B. L., Nitsch, D., dos Santos Silva, I., McCormack, V., Hardy, R., Mann, V., et al. (2006). Statistical issues in life course epidemiology. American Journal of Epidemiology, 163(1), 84-96.

Demerath, E. W., Schubert, C. M., Maynard, L. M., Sun, S. S., Chumlea, W. C., Pickoff, A., et al. (2006). Do changes in body mass index percentile reflect changes in body composition in children? Data from the Fels Longitudinal Study. Pediatrics, 117(3), e487-e495.

Dieffenbach, S., \& Stein, A. D. (2012). Stunted child/overweight mother pairs represent a statistical artifact, not a distinct entity. Journal of Nutrition, 142(4), 771-773.

Dorner, G. (1973). Possible significance of prenatal and-or perinatal nutrition for the pathogenesis of obesity. Acta Biologica et Medica Germanica, 30(5), K19-K22.

Dorner, G., Haller, H., \& Leonhardt, W. (1973). Possible significance of pre- and or early postnatal nutrition in the pathogenesis of arteriosclerosis. Acta Biologica et Medica Germanica, 31(5), K31-K35.

Druet, C., Stettler, N., Sharp, S., Simmons, R. K., Cooper, C., Smith, G. D., et al. (2012). Prediction of childhood obesity by infancy weight gain: An individual-level meta-analysis. Paediatric and Perinatal Epidemiology, 26(1), 19-26.

Dunger, D. B., Ahmed, M. L., \& Ong, K. K. (2005). Effects of obesity on growth and puberty. Best Practice and Research Clinical Endocrinology and Metabolism, 19(3), 375-390. 
Ebong, I. A., Watson, K. E., Goff, D. C., Jr., Bluemke, D. A., Srikanthan, P., Horwich, T., et al. (2014). Age at menopause and incident heart failure: The Multi-Ethnic Study of Atherosclerosis. Menopause, 21(6), 585-591.

Ellison, P. T., \& Reiches, M. W. (2012). Puberty. In N. Cameron \& B. Bogin (Eds.), Human growth and development (2nd ed., pp. 81-107). London: Academic.

Emerging Risk Factors Collaboration. (2012). Adult height and the risk of cause-specific death and vascular morbidity in 1 million people: Individual participant meta-analysis. International Journal of Epidemiology, 41(5), 1419-1433.

Eriksson, J. G., Forsen, T., Tuomilehto, J., Osmond, C., \& Barker, D. J. (2003a). Early adiposity rebound in childhood and risk of Type 2 diabetes in adult life. Diabetologia, 46(2), 190-194.

Eriksson, J. G., Forsen, T. J., Osmond, C., \& Barker, D. J. (2003b). Pathways of infant and childhood growth that lead to type 2 diabetes. Diabetes Care, 26(11), 3006-3010.

Eriksson, J. G., Forsen, T. J., Kajantie, E., Osmond, C., \& Barker, D. J. (2007). Childhood growth and hypertension in later life. Hypertension, 49(6), 1415-1421.

Foresight. (2008). Foresight mental capital and wellbeing project. Final project report. London: The Government Office for Science.

Forsdahl, A. (1977). Are poor living conditions in childhood and adolescence an important risk factor for arteriosclerotic heart disease? British Journal of Preventive and Social Medicine, 31(2), 91-95.

Forsen, T. J., Eriksson, J. G., Osmond, C., \& Barker, D. J. (2004). The infant growth of boys who later develop coronary heart disease. Annals of Medicine, 36(5), 389-392.

Freinkel, N. (1980). Banting Lecture 1980. Of pregnancy and progeny. Diabetes, 29(12), 1023 1035.

Frongillo, E. A., Jr., de Onis, M., \& Hanson, K. M. (1997). Socioeconomic and demographic factors are associated with worldwide patterns of stunting and wasting of children. Journal of Nutrition, 127(12), 2302-2309.

Gillman, M. W., Rifas-Shiman, S., Berkey, C. S., Field, A. E., \& Colditz, G. A. (2003). Maternal gestational diabetes, birth weight, and adolescent obesity. Pediatrics, 111(3), e221-e226.

Gluckman, P. D. (1995). Clinical review 68: The endocrine regulation of fetal growth in late gestation: The role of insulin-like growth factors. Journal of Clinical Endocrinology and Metabolism, 80(4), 1047-1050.

Godfrey, K., Robinson, S., Barker, D. J., Osmond, C., \& Cox, V. (1996). Maternal nutrition in early and late pregnancy in relation to placental and fetal growth. British Medical Journal, 312(7028), 410-414.

Gordon-Larsen, P., Adair, L. S., Nelson, M. C., \& Popkin, B. M. (2004). Five-year obesity incidence in the transition period between adolescence and adulthood: The National Longitudinal Study of Adolescent Health. American Journal of Clinical Nutrition, 80(3), 569-575.

Gropper, S. S., Simmons, K. P., Connell, L. J., \& Ulrich, P. V. (2012). Weight and body composition changes during the first three years of college. Journal of Obesity, 2012, 634048.

Hackett, J. A., Sengupta, R., Zylicz, J. J., Murakami, K., Lee, C., Down, T. A., et al. (2013). Germline DNA demethylation dynamics and imprint erasure through 5hydroxymethylcytosine. Science, 339(6118), 448-452.

Hales, C. N., Barker, D. J., Clark, P. M., Cox, L. J., Fall, C., Osmond, C., et al. (1991). Fetal and infant growth and impaired glucose tolerance at age 64. British Medical Journal, 303(6809), $1019-1022$.

Harder, T., Rodekamp, E., Schellong, K., Dudenhausen, J. W., \& Plagemann, A. (2007). Birth weight and subsequent risk of type 2 diabetes: A meta-analysis. American Journal of Epidemiology, 165(8), 849-857.

Harding, J. E. (2001). The nutritional basis of the fetal origins of adult disease. International Journal of Epidemiology, 30(1), 15-23.

Hardy, R., Kuh, D., Langenberg, C., \& Wadsworth, M. E. (2003). Birthweight, childhood social class, and change in adult blood pressure in the 1946 British birth cohort. Lancet, 362(9391), 1178-1183. 
Hardy, R., Kuh, D., Whincup, P. H., \& Wadsworth, M. E. (2006a). Age at puberty and adult blood pressure and body size in a British birth cohort study. Journal of Hypertension, 24(1), 59-66.

Hardy, R., Sovio, U., King, V. J., Skidmore, P. M., Helmsdal, G., Olsen, S. F., et al. (2006b). Birthweight and blood pressure in five European birth cohort studies: An investigation of confounding factors. European Journal of Public Health, 16(1), 21-30.

Holliday, R. (1994). Epigenetics: An overview. Developmental Genetics, 15(6), 453-457.

Holmes, M. V., Lange, L. A., Palmer, T., Lanktree, M. B., North, K. E., Almoguera, B., et al. (2014). Causal effects of body mass index on cardiometabolic traits and events: A Mendelian randomization analysis. The American Journal of Human Genetics, 94(2), 198-208.

Huxley, R., Neil, A., \& Collins, R. (2002). Unravelling the fetal origins hypothesis: Is there really an inverse association between birthweight and subsequent blood pressure? Lancet, 360(9334), $659-665$.

Johnson, W. (2014). Analytical strategies in human growth research. American Journal of Human Biology, 27, 69-83.

Johnson, W., Soloway, L. E., Erickson, D., Choh, A. C., Lee, M., Chumlea, W. C., et al. (2012a). A changing pattern of childhood BMI growth during the 20th century: $70 \mathrm{y}$ of data from the Fels Longitudinal Study. American Journal of Clinical Nutrition, 95(5), 1136-1143.

Johnson, W., Stovitz, S. D., Choh, A. C., Czerwinski, S. A., Towne, B., \& Demerath, E. W. (2012b). Patterns of linear growth and skeletal maturation from birth to 18 years of age in overweight young adults. International Journal of Obesity, 36(4), 535-541.

Johnson, W., Choh, A. C., Curran, J. E., Czerwinski, S. A., Bellis, C., Dyer, T. D., et al. (2013a). Genetic risk for earlier menarche also influences peripubertal body mass index. American Journal of Physical Anthropology, 150(1), 10-20.

Johnson, W., Choh, A. C., Lee, M., Towne, B., Czerwinski, S. A., \& Demerath, E. W. (2013b). Characterization of the infant BMI peak: Sex differences, birth year cohort effects, association with concurrent adiposity, and heritability. American Journal of Human Biology, 25(3), 378388.

Johnson, W., Kuh, D., Tikhonoff, V., Charakida, M., Woodside, J., Whincup, P., et al. (2014). Body mass index and height from infancy to adulthood and carotid intima-media thickness at 60 to 64 years in the 1946 British birth cohort study. Arteriosclerosis, Thrombosis, and Vascular Biology, 34(3), 654-660.

Juonala, M., Magnussen, C. G., Berenson, G. S., Venn, A., Burns, T. L., Sabin, M. A., et al. (2011). Childhood adiposity, adult adiposity, and cardiovascular risk factors. New England Journal of Medicine, 365(20), 1876-1885.

Kerkhof, G. F., \& Hokken-Koelega, A. C. (2012). Rate of neonatal weight gain and effects on adult metabolic health. Nature Reviews Endrocrinology, 8(11), 689-692.

Kermack, W. O., McKendrick, A. G., \& McKinlay, P. L. (2001). Death-rates in Great Britain and Sweden. Some general regularities and their significance. International Journal of Epidemiology, 30(4), 678-683.

Kilpelainen, T. O., Qi, L., Brage, S., Sharp, S. J., Sonestedt, E., Demerath, E., et al. (2011). Physical activity attenuates the influence of FTO variants on obesity risk: A meta-analysis of 218,166 adults and 19,268 children. PLoS Medicine, 8(11), e1001116.

Koenen, K. C., Rudenstine, S., Susser, E., \& Galea, S. (2013). A life course approach to mental disorders. Oxford: Oxford University Press.

Kramer, M. S. (1987). Determinants of low birth weight: Methodological assessment and metaanalysis. Bulletin of the World Health Organization, 65(5), 663-737.

Krieger, N. (2013). Epidemiology and the people's health: Theories and context. New York: Oxford University Press.

Kuh, D., \& Ben-Shlomo, Y. (2004). A life course approach to chronic disease epidemiology (2nd ed.). Oxford: Oxford University Press.

Kuh, D., \& Hardy, R. (2002). A life course approach to women's health. Oxford: Oxford University Press.

Kuh, D., Ben-Shlomo, Y., Lynch, J., Hallqvist, J., \& Power, C. (2003). Life course epidemiology. Journal of Epidemiology and Community Health, 57(10), 778-783. 
Kuh, D., Cooper, R., Hardy, R., Richards, M., \& Ben-Shlomo, Y. (2013). A life course approach to healthy ageing. Oxford: Oxford University Press.

Lampl, M., Kuzawa, C. W., \& Jeanty, P. (2002). Infants thinner at birth exhibit smaller kidneys for their size in late gestation in a sample of fetuses with appropriate growth. American Journal of Human Biology, 14(3), 398-406.

Langenberg, C., Hardy, R., Kuh, D., \& Wadsworth, M. E. (2003). Influence of height, leg and trunk length on pulse pressure, systolic and diastolic blood pressure. Journal of Hypertension, 21(3), 537-543.

Law, C. M., Barker, D. J., Osmond, C., Fall, C. H., \& Simmonds, S. J. (1992). Early growth and abdominal fatness in adult life. Journal of Epidemiology and Community Health, 46(3), 184-186.

Lawlor, D. A., \& Mishra, G. (2009). Designing, analysing and understanding family based studies in life course epidemiology. Oxford: Oxford University Press.

Lawlor, D. A., Ebrahim, S., \& Smith, G. D. (2003). The association of socio-economic position across the life course and age at menopause: The British Women's Heart and Health Study. BJOG, 110(12), 1078-1087.

Lawlor, D. A., Harbord, R. M., Sterne, J. A., Timpson, N., \& Davey Smith, G. (2008). Mendelian randomization: Using genes as instruments for making causal inferences in epidemiology. Statistics in Medicine, 27(8), 1133-1163.

Lawlor, D. A., Lichtenstein, P., \& Langstrom, N. (2011). Association of maternal diabetes mellitus in pregnancy with offspring adiposity into early adulthood: Sibling study in a prospective cohort of 280,866 men from 248,293 families. Circulation, 123(3), 258-265.

Li, S., Chen, W., Srinivasan, S. R., Xu, J., \& Berenson, G. S. (2012). Relation of childhood obesity/cardiometabolic phenotypes to adult cardiometabolic profile: The Bogalusa Heart Study. American Journal of Epidemiology, 176(Suppl 7), S142-S149.

Littman, A. J., Jacobson, I. G., Boyko, E. J., Powell, T. M., \& Smith, T. C. (2013). Weight change following US military service. International Journal of Obesity, 37(2), 244-253.

Lumey, L. H., Stein, A. D., Kahn, H. S., \& Romijn, J. A. (2009). Lipid profiles in middle-aged men and women after famine exposure during gestation: The Dutch Hunger Winter Families Study. American Journal of Clinical Nutrition, 89(6), 1737-1743.

Luyckx, V. A., \& Brenner, B. M. (2005). Low birth weight, nephron number, and kidney disease. Kidney International Supplement, 68(97), S68-S77.

Marmot, M. G. (2010). Fair society, healthy lives: The Marmot review. London: UCL Institute of Health Equity.

Marmot, M. G., Shipley, M. J., \& Rose, G. (1984). Inequalities in death-specific explanations of a general pattern? Lancet, 1(8384), 1003-1006.

Martorell, R., \& Young, M. F. (2012). Patterns of stunting and wasting: Potential explanatory factors. Advances in Nutrition, 3(2), 227-233.

Martyn, C. N., Barker, D. J., \& Osmond, C. (1996). Mothers' pelvic size, fetal growth, and death from stroke and coronary heart disease in men in the UK. Lancet, 348(9037), 1264-1268.

McAllister, E. J., Dhurandhar, N. V., Keith, S. W., Aronne, L. J., Barger, J., Baskin, M., et al. (2009). Ten putative contributors to the obesity epidemic. Critical Reviews in Food Science and Nutrition, 49(10), 868-913.

Metcalf, B. S., Hosking, J., Fremeaux, A. E., Jeffery, A. N., Voss, L. D., \& Wilkin, T. J. (2011). BMI was right all along: Taller children really are fatter (implications of making childhood BMI independent of height) EarlyBird 48. International Journal of Obesity, 35(4), 541-547.

Monasta, L., Batty, G. D., Cattaneo, A., Lutje, V., Ronfani, L., Van Lenthe, F. J., et al. (2010). Early-life determinants of overweight and obesity: A review of systematic reviews. Obesity Reviews, 11(10), 695-708.

Morandi, A., Meyre, D., Lobbens, S., Kleinman, K., Kaakinen, M., Rifas-Shiman, S. L., et al. (2012). Estimation of newborn risk for child or adolescent obesity: Lessons from longitudinal birth cohorts. PloS One, 7(11), e49919.

Morris, J. K., Cook, D. G., \& Shaper, A. G. (1992). Non-employment and changes in smoking, drinking, and body weight. British Medical Journal, 304(6826), 536-541. 
Mumby, H. S., Elks, C. E., Li, S., Sharp, S. J., Khaw, K. T., Luben, R. N., et al. (2011). Mendelian Randomisation Study of Childhood BMI and Early Menarche. Journal of Obesity, 2011, 180729.

Murray, E. T., Mishra, G. D., Kuh, D., Guralnik, J., Black, S., \& Hardy, R. (2011). Life course models of socioeconomic position and cardiovascular risk factors: 1946 birth cohort. Annals of Epidemiology, 21(8), 589-597.

Newman, C. G. (1986). The thalidomide syndrome: Risks of exposure and spectrum of malformations. Clinics in Perinatology, 13(3), 555-573.

Omran, A. R. (1971). The epidemiologic transition. A theory of the epidemiology of population change. Milbank Memorial Fund Quarterly, 49(4), 509-538.

Ong, K. K., \& Loos, R. J. (2006). Rapid infancy weight gain and subsequent obesity: Systematic reviews and hopeful suggestions. Acta Paediatrica, 95(8), 904-908.

Ortega, F. B., Lee, D. C., Katzmarzyk, P. T., Ruiz, J. R., Sui, X., Church, T. S., et al. (2013). The intriguing metabolically healthy but obese phenotype: Cardiovascular prognosis and role of fitness. European Heart Journal, 34(5), 389-397.

Osmond, C., Barker, D. J., Winter, P. D., Fall, C. H., \& Simmonds, S. J. (1993). Early growth and death from cardiovascular disease in women. British Medical Journal, 307(6918), 1519-1524.

Osmond, C., Kajantie, E., Forsen, T. J., Eriksson, J. G., \& Barker, D. J. (2007). Infant growth and stroke in adult life: The Helsinki birth cohort study. Stroke, 38(2), 264-270.

Owen, C. G., Whincup, P. H., Orfei, L., Chou, Q. A., Rudnicka, A. R., Wathern, A. K., et al. (2009). Is body mass index before middle age related to coronary heart disease risk in later life? Evidence from observational studies. International Journal of Obesity, 33(8), 866-877.

Paajanen, T. A., Oksala, N. K., Kuukasjarvi, P., \& Karhunen, P. J. (2010). Short stature is associated with coronary heart disease: A systematic review of the literature and a metaanalysis. European Heart Journal, 31(14), 1802-1809.

Painter, R. C., Osmond, C., Gluckman, P., Hanson, M., Phillips, D. I., \& Roseboom, T. J. (2008). Transgenerational effects of prenatal exposure to the Dutch famine on neonatal adiposity and health in later life. BJOG, 115(10), 1243-1249.

Park, M. H., Sovio, U., Viner, R. M., Hardy, R. J., \& Kinra, S. (2013). Overweight in childhood, adolescence and adulthood and cardiovascular risk in later life: Pooled analysis of three British birth cohorts. PloS One, 8(7), e70684.

Phillips, D. I. (1996). Insulin resistance as a programmed response to fetal undernutrition. Diabetologia, 39(9), 1119-1122.

Phillips, D. I., Cooper, C., Fall, C., Prentice, L., Osmond, C., Barker, D. J., et al. (1993). Fetal growth and autoimmune thyroid disease. Quarterly Journal of Medicine, 86(4), 247-253.

Pickles, A., Maughan, B., \& Wadsworth, M. (2007). Epidemiological methods in life course research. Oxford: Oxford University Press.

Pierce, M. B., Kuh, D., \& Hardy, R. (2012). The role of BMI across the life course in the relationship between age at menarche and diabetes, in a British Birth Cohort. Diabetic Medicine, 29(5), 600-603.

Prentice, P., \& Viner, R. M. (2013). Pubertal timing and adult obesity and cardiometabolic risk in women and men: A systematic review and meta-analysis. International Journal of Obesity, 37(8), 1036-1043.

Rao, G. H., Thethi, I., \& Fareed, J. (2011). Vascular disease: Obesity and excess weight as modulators of risk. Expert Review of Cardiovascular Therapy, 9(4), 525-534.

Ravelli, G. P., Stein, Z. A., \& Susser, M. W. (1976). Obesity in young men after famine exposure in utero and early infancy. New England Journal of Medicine, 295(7), 349-353.

Ravelli, A. C., van der Meulen, J. H., Michels, R. P., Osmond, C., Barker, D. J., Hales, C. N., et al. (1998). Glucose tolerance in adults after prenatal exposure to famine. Lancet, 351(9097), 173-177.

Roberson, L. L., Aneni, E. C., Maziak, W., Agatston, A., Feldman, T., Rouseff, M., et al. (2014). Beyond BMI: The "Metabolically healthy obese" phenotype \& its association with clinical/subclinical cardiovascular disease and all-cause mortality - a systematic review. BMC Public Health, 14(1), 14. 
Rolland-Cachera, M. F., \& Peneau, S. (2013). Growth trajectories associated with adult obesity. World Review of Nutrition and Dietetics, 106, 127-134.

Rolland-Cachera, M. F., Deheeger, M., Bellisle, F., Sempe, M., Guilloud-Bataille, M., \& Patois, E. (1984). Adiposity rebound in children: A simple indicator for predicting obesity. American Journal of Clinical Nutrition, 39(1), 129-135.

Rosenberg, M. A., Lopez, F. L., Buzkova, P., Adabag, S., Chen, L. Y., Sotoodehnia, N., et al. (2013). Height and risk of sudden cardiac death: The Atherosclerosis Risk in Communities and Cardiovascular Health Studies. Annals of Epidemiology, 24(3), 174-179.

Rosmond, R., \& Bjorntorp, P. (2000). The hypothalamic-pituitary-adrenal axis activity as a predictor of cardiovascular disease, type 2 diabetes and stroke. Journal of Internal Medicine, 247(2), 188-197.

Schellong, K., Schulz, S., Harder, T., \& Plagemann, A. (2012). Birth weight and long-term overweight risk: Systematic review and a meta-analysis including 643,902 persons from 66 studies and 26 countries globally. PloS One, 7(10), e47776.

Schmidt, M., Botker, H. E., Pedersen, L., \& Sorensen, H. T. (2013). Adult height and risk of ischemic heart disease, atrial fibrillation, stroke, venous thromboembolism, and premature death: A population based 36-year follow-up study. European Journal of Epidemiology, 29(2), $111-118$.

Scientific Advisory Committee. (2011). Opinion paper 27: Why should we consider a life course approach to women's health care. London: Royal College of Obstetricians and Gynaecologists.

Scott, J. P. (1986). Critical periods in organizational processes. In F. Falkner \& J. M. Tanner (Eds.), Human growth: A comprehensive treatise (Methodology; ecological, genetic and nutritional effects on growth, Vol. 3, pp. 181-196). New York: Plenum Press.

Silverwood, R. J., De Stavola, B. L., Cole, T. J., \& Leon, D. A. (2009). BMI peak in infancy as a predictor for later BMI in the Uppsala Family Study. International Journal of Obesity, 33(8), 929-937.

Skidmore, P. M., Hardy, R. J., Kuh, D. J., Langenberg, C., \& Wadsworth, M. E. (2007). Life course body size and lipid levels at 53 years in a British birth cohort. Journal of Epidemiology and Community Health, 61(3), 215-220.

Sovio, U., Kaakinen, M., Tzoulaki, I., Das, S., Ruokonen, A., Pouta, A., et al. (2014). How do changes in body mass index in infancy and childhood associate with cardiometabolic profile in adulthood? Findings from the Northern Finland Birth Cohort 1966 Study. International Journal of Obesity, 38(1), 53-59.

Stein, Z., \& Susser, M. (1975). The Dutch famine, 1944-1945, and the reproductive process. I. Effects on six indices at birth. Pediatric Research, 9(2), 70-76.

Stein, C. E., Fall, C. H., Kumaran, K., Osmond, C., Cox, V., \& Barker, D. J. (1996). Fetal growth and coronary heart disease in south India. Lancet, 348(9037), 1269-1273.

Swinburn, B. A., Sacks, G., Hall, K. D., McPherson, K., Finegood, D. T., Moodie, M. L., et al. (2011). The global obesity pandemic: Shaped by global drivers and local environments. Lancet, 378(9793), 804-814.

Taylor, R. W., Goulding, A., Lewis-Barned, N. J., \& Williams, S. M. (2004). Rate of fat gain is faster in girls undergoing early adiposity rebound. Obesity Research, 12(8), 1228-1230.

Taylor, R. W., Grant, A. M., Goulding, A., \& Williams, S. M. (2005). Early adiposity rebound: Review of papers linking this to subsequent obesity in children and adults. Current Opinion in Clinical Nutrition and Metabolic Care, 8(6), 607-612.

The, N. S., \& Gordon-Larsen, P. (2009). Entry into romantic partnership is associated with obesity. Obesity (Silver Spring), 17(7), 1441-1447.

Tian, J. Y., Cheng, Q., Song, X. M., Li, G., Jiang, G. X., Gu, Y. Y., et al. (2006). Birth weight and risk of type 2 diabetes, abdominal obesity and hypertension among Chinese adults. European Journal of Endocrinology, 155(4), 601-607.

Tu, Y. K., West, R., Ellison, G. T., \& Gilthorpe, M. S. (2005). Why evidence for the fetal origins of adult disease might be a statistical artifact: The "reversal paradox" for the relation between birth weight and blood pressure in later life. American Journal of Epidemiology, 161(1), $27-32$. 
Tu, Y. K., Tilling, K., Sterne, J. A., \& Gilthorpe, M. S. (2013). A critical evaluation of statistical approaches to examining the role of growth trajectories in the developmental origins of health and disease. International Journal of Epidemiology, 42(5), 1327-1339.

Varela-Silva, M. I., Dickinson, F., Wilson, H., Azcorra, H., Griffiths, P. L., \& Bogin, B. (2012). The nutritional dual-burden in developing countries-how is it assessed and what are the health implications? Collegium Antropologicum, 36(1), 39-45.

Verbeeten, K. C., Elks, C. E., Daneman, D., \& Ong, K. K. (2011). Association between childhood obesity and subsequent Type 1 diabetes: A systematic review and meta-analysis. Diabetic Medicine, 28(1), 10-18.

Wadsworth, M. E., Hardy, R. J., Paul, A. A., Marshall, S. F., \& Cole, T. J. (2002). Leg and trunk length at 43 years in relation to childhood health, diet and family circumstances; evidence from the 1946 national birth cohort. International Journal of Epidemiology, 31(2), 383-390.

Wells, J. C., Chomtho, S., \& Fewtrell, M. S. (2007). Programming of body composition by early growth and nutrition. Proceedings of the Nutrition Society, 66(3), 423-434.

Wells, J. C., Dumith, S. C., Ekelund, U., Reichert, F. F., Menezes, A. M., Victora, C. G., et al. (2012). Associations of intrauterine and postnatal weight and length gains with adolescent body composition: Prospective birth cohort study from Brazil. Journal of Adolescent Health, 51(6 Suppl), S58-S64.

Weng, S. F., Redsell, S. A., Swift, J. A., Yang, M., \& Glazebrook, C. P. (2012). Systematic review and meta-analyses of risk factors for childhood overweight identifiable during infancy. Archives of Disease in Childhood, 97(12), 1019-1026.

Whincup, P. H., Kaye, S. J., Owen, C. G., Huxley, R., Cook, D. G., Anazawa, S., et al. (2008). Birth weight and risk of type 2 diabetes: A systematic review. Journal of the American Medical Association, 300(24), 2886-2897.

Whitlock, G., Lewington, S., Sherliker, P., Clarke, R., Emberson, J., Halsey, J., et al. (2009). Body-mass index and cause-specific mortality in 900000 adults: Collaborative analyses of 57 prospective studies. Lancet, 373(9669), 1083-1096.

Woodall, S. M., Johnston, B. M., Breier, B. H., \& Gluckman, P. D. (1996). Chronic maternal undernutrition in the rat leads to delayed postnatal growth and elevated blood pressure of offspring. Pediatric Research, 40(3), 438-443.

Yajnik, C. S., Fall, C. H., Coyaji, K. J., Hirve, S. S., Rao, S., Barker, D. J., et al. (2003). Neonatal anthropometry: The thin-fat Indian baby. The Pune Maternal Nutrition Study. International Journal of Obesity, 27(2), 173-180.

Yusuf, S., Reddy, S., Ounpuu, S., \& Anand, S. (2001). Global burden of cardiovascular diseases: Part I: General considerations, the epidemiologic transition, risk factors, and impact of urbanization. Circulation, 104(22), 2746-2753.

World Health Organisation Department of Noncommunicable Disease Prevention and Health Promotion. (2001). Life course perspectives on coronary heart disease, stroke and diabetes: Key issues and implications for policy and research: Summary report of a meeting of experts, 2-4 May 2001. Geneva: World Health Organisation. 